EVIDENCE BASED PUBLIC HEALTH POLICY AND PRACTICE

\title{
Equity of access to health care: outlining the foundations for action
}

\author{
Adam Oliver, Elias Mossialos
}

J Epidemiol Community Health 2004;58:655-658. doi: 10.1136/jech.2003.017731

The Ministers of Health from Chile, Germany, Greece, New Zealand, Slovenia, Sweden, and the United Kingdom recently established The International Forum on Common Access to Health Care Services, based on a common belief that their citizens should enjoy universal and equitable access to good quality health care. The ministers intend to form a network to share thinking and evidence on healthcare improvements, with the specific aim of sustaining and promoting equitable access to health care. Despite a vast literature on the notion of equity of access, little agreement has been reached in the literature on exactly what this notion ought to mean. This article provides a brief description of the relevance of the access principle of equity, and summarises the research programme that is necessary for turning the principle into a useful, operational policy objective.

See end of article for authors' affiliations

Correspondence to: Dr A Oliver, LSE Health and Social Care, London School of Economics and Political Science, London WC2A 2AE, UK :

a.j.oliver@|se.ac.uk

Accepted for publication 2 January 2004 n January and in May 2003, Ministers of Health from Chile, Germany, Greece, New Zealand, Slovenia, Sweden, and the United Kingdom met in Stockholm and London, respectively, for the purpose of forming an international forum on matters relating to access to healthcare services (The International Forum on Common Access to Health Care Services). ${ }^{1}$ The ministers agreed that they share a common belief that their healthcare systems should aim to ensure that their citizens enjoy universal and equitable access to good quality health care. Moreover, they asserted that they are united by a desire to hold true to this belief in the face of often cited challenges to all healthcare systems, such as aging populations, increasing cost pressures, and rising public expectations. The Group concluded that they would form an international network for sharing progressive thinking and evidence on healthcare improvements with the aim of sustaining the goal of equitable access to healthcare services. The International Forum on Common Access to Health Care Services thus provides a uniquely proactive attempt by senior policy makers in several countries to encourage methodological and practical developments in the area of healthcare access, and the ministers will continue to meet to consolidate this network.

However, despite frequent references to, and common rhetoric around, "equitable access to health care", little agreement has been reached in the health and healthcare related literature on the specific meaning of this notion. The absence of a commonly accepted specific definition of "equitable access" is problematic, because governments are left without a reference point against which to judge the consistency of their healthcare policies. For example, many countries within the European Union have attempted to improve "access" by introducing waiting time guarantees and patients' rights legislation, and by developing their resource allocation mechanisms and expanding statutory healthcare coverage. ${ }^{2}$ Yet many of these governments have also very possibly undermined equitable access by introducing and increasing user charges for ambulatory and inpatient services. ${ }^{2}$

It is not the objective of this article to review the extensive literature that purports to address the various, and often conflicting, notions of equity, access and/or need. Rather, for the current and future members of the aforementioned network, and indeed for the broader research and policy communities, this article provides a brief description of the relevance of the access principle of equity, and summarises the research programme that is necessary for turning the principle into a useful, operational policy objective.

\section{PRINCIPLES OF EQUITY}

There is an enormous literature on equity in health and health care, written from every conceivable disciplinary perspective, and several principles of equity are commonly discussed. ${ }^{34}$ For example:

- Equal access to health care for those in equal need of health care.

- Equal utilisation of health care for those in equal need of health care.

- Equal (or, rather, equitable) health outcomes (as measured by, for example, quality adjusted life expectancy).

Equal access for equal need requires conditions whereby those with equal needs have equal opportunities to access health care (that is, horizontal equity), and, as a corollary, those with unequal needs have appropriately unequal opportunities to access health care (that is, vertical equity). For various acceptable reasons (for example, varying individual preferences), those in equal need and with equal opportunities to access health care may not make an equal use of those opportunities. These acceptable reasons should not be confused with unacceptable reasons for differential use of health care. For example, some individuals (or groups of individuals) may 
be better informed and more adept at accessing—and making full use of-health care than others.

As is implied in the terminology, equal utilisation for equal need requires conditions whereby those who have an equal need for health care make equal use of health care. Compared with equal access for equal need, this equity principle therefore requires more proactive (and possibly very costly) efforts by policy makers, and would require that potentially acceptable reasons for unequal use of healthcare services (by those in equal need) be overridden. For example, differences in lifestyle preferences and/or levels of risk aversion may lead to differences in the utilisation of health care, but the principle of equal utilisation for equal need does not allow for these considerations.

The principle of achieving equal health outcomes (for example, mortality and morbidity measurements) is potentially highly undesirable because it would require too many restrictions on the ways in which people may choose to live their lives. However, the attainment of less unequal health outcomes (that is, more equitable health outcomes) may be a desirable policy objective, but the extent to which the focus of this article-that is, health care-influences average levels of, and differentials in, population health outcomes is limited. ${ }^{5}$ Other areas of fiscal and social policy, that impinge upon, for example, incomes, education, housing conditions, and nutrition, are potentially far stronger influences, perhaps in large part because they better tackle the fundamental determinants of health. Moreover, the extent to which health care (in particular, curative health care) is used as a vessel to redistribute health outcomes is morally contentious, because this action would require people who are already ill and have the same need for health care to be treated unequally (and in line with some factor that is exogenous to their health-for example, their level of income or educational attainment, among other possible factors).

Hence, in agreement with the seven Ministers of Health who met in Stockholm and London, we contend that equal access to health care for those in equal need is the most appropriate principle of equity for the healthcare policy maker to pursue, because ( 1 ) it is specific to health care and does not require that we discriminate between people who are already ill purely on the basis of factors that are exogenous to their health, and (2) it respects acceptable reasons for differentials in healthcare utilisation by those in equal need.

\section{RELEVANT GROUPS FOR CONSIDERATION}

There are many groups over which the policy maker might wish to secure equal access to health care for equal need. These include those defined by: income; social class; geographical residence; education; ethnicity; gender; lifestyle. Differences in access for those in equal need across all of these groups are potentially important. However, policy action that is very specifically designed to address inequities in (a well defined definition of) access is embryonic (at best), and initially it is perhaps sensible to limit the scope of action to group differentials that appear to offer a direct challenge to fundamental societal values.

For example, most European, and many non-European, healthcare systems are based upon the fundamental notion (or value) of social solidarity; that is, that people ought to have equal access to a reasonable minimum range and standard of health care irrespective of their ability to pay for health care. Groups defined by income relate directly to the solidarity principle and thus one could argue that violations of the principle of equal access for equal need across groups defined by income ought to form a focus for governmental concern in these countries. This is not to say that unequal access across other groups will be unimportant; for example, geographically defined differential access between urban and rural areas is likely to be a particular cause of concern. It is merely to say that inequalities in access across some groups (for example, across groups defined by income) perhaps offer a relatively more salient challenge to social justice that those that prevail across other groups. Therefore, it may be sensible for the policy maker to concentrate initially on-or to "prioritise" those groups that most closely relate to core societal values (and, following a period of intra-country deliberation, the groups that will be prioritised through this process may vary from country to country).

\section{DEFINITIONS OF ACCESS AND NEED \\ Access}

As mentioned above, equal access for equal need is a frequently discussed and cited principle both in the academic literature and in government policy documents, ${ }^{6}$ but there are currently no generally accepted definitions of access and need. Utilisation is often (indeed, usually) inappropriately used as a proxy for access, even by those who have written prolifically on the subject of equity in health and health care. ${ }^{7}$ Other academic leaders in the field have more carefully defined access to health care, at a general level, as entailing the ability to secure a specified set of healthcare services, at a specified level of quality, subject to a specified maximum level of personal inconvenience and cost, while in possession of a specified amount of information. ${ }^{8}$

The word "specified" allows policy makers to shape access towards country (or even regional) specific circumstances, in particular allowing the range of healthcare services to which access should apply to depend on the availability of resources to finance health care. This point is of great significance to the International Forum on Common Access to Health Care Services, where, for example, the Ministers of Health in Slovenia and Chile may not be able to commit themselves to the levels of service that are available in Germany and Sweden. Therefore, importantly, the concept of access does not necessarily operate in isolation from the responsibility to pay for providing access. Hence, this definition renders it acceptable that access may vary across countries, and, within countries, may refer only to a reasonable minimum specified range and quality of healthcare service (and thus may not apply to health care services that are considered in some sense "superficial", such as hotel services in hospitals ${ }^{4}$ ). Nevertheless, the general definition points the policy maker towards the relevant factors for consideration (that is, the relevant range and quality of healthcare services, the inconvenience, disutility, time costs, and financial costs of securing those services, and the information required to take advantage of those services). If adopted, the general definition can thus serve to provide a standard against which "current" access can be judged, and can therefore help policy makers to observe how they can improve, and whether they are improving, equity of access over the population for which they have jurisdiction.

\section{Need}

Discussions of "social" need have a long history, dating back to Bradshaw's seminal work in which he defined need along the following four dimensions?: (1) normative need, in which an expert, professional administrator, or scientist defines need by laying down their desired standard and comparing it with the standard that actually exists; (2) felt need, in which need is equated with want, and is assessed by simply asking a person or population if they feel they need a service; (3) expressed need, where felt need is turned into action; (4) comparative need, where the characteristics of a population who receive a service are ascertained, and where people with 
similar characteristics who do not receive the service are adjudged to be in need.

Despite much ensuing debate regarding need in the years since Bradshaw's analysis, ${ }^{10}$ there remains quite stark disagreement as to what constitutes "need" for health care, and it is clear that understanding, defining, measuring, and comparing the needs that are related to individual health problems/illnesses will be a difficult and highly complex task. Although not our direct interest in this article, formulas, developed for the purpose of informing regional healthcare resource allocations, have been developed in several countries. These formulas use proxies for need that are sometimes quite heavily based on mortality and morbidity indicators, as in England and Wales, ${ }^{11}$ and sometimes on socioeconomic characteristics, as in Sweden. ${ }^{12}$ "Need", in these cases, is estimated on the basis of the extent to which these characteristics (that is, mortality, morbidity, socioeconomic circumstances) contribute towards historical patterns in the utilisation of healthcare services, and reflects Bradshaw's notion of comparative need. However, as noted above, need, in itself, has remained a much debated concept, and cross disciplinary consensus on an operational definition of need has not yet been reached. Moreover, healthcare utilisation may have very little correlation with any fundamental notion of health care need. Therefore, the proxies for need that are generally used in resource allocation formulas (that is, mortality, morbidity, and/or socioeconomic factors, the choice of which is often driven by data availability), and the methods by which the relative "importance" of these proxies are currently estimated (that is, through healthcare utilisation data), both have the potential to mislead.

Much work needs to be undertaken to develop a generally accepted working definition of need, but two components stand out as important:

- The state of the individual's pre-treatment health (with greater ill health equating to greater need, which is the definition currently embraced by most clinicians).

- The individual's capacity to benefit from health care (with the amount of healthcare resources required to exhaust an individual's capacity to benefit from health care determining the size of their need, which is the definition currently embraced by most health economists). ${ }^{4}$

These two components of need, taken by themselves, will sometimes conflict with one another. For example, there may be no effective healthcare treatments (that is, little or no capacity to benefit) for some highly debilitating illnesses (that is, high levels of pre-treatment ill health); for example, advanced lung cancer. Nevertheless, both components are potentially important, and a clear operational definition that combines them in a manner that generates general acceptance is an important area for future research and consensus (interested readers might like to refer to the work of Erik Nord for a perspective on how clinical need and capacity to benefit could perhaps be combined in the valuation of health outcomes $\left.^{13}\right)$. For our purposes of stimulating constructive research on this issue, it is sufficient to merely acknowledge their potential importance.

\section{FACTORS THAT INFLUENCE EQUAL ACCESS FOR EQUAL NEED}

Many different factors potentially impact on differential access to health care across different groups. With current information, it is difficult to disentangle these to form a fully comprehensive and coherent policy response. ${ }^{8}$ However, for illustrative purposes, some general comments can be made with respect to groups defined by income, geographical residence, and ethnicity.

\section{The supply side}

On the supply side, and with respect to groups defined by geographical residence, the geographical proximity to healthcare services varies quite considerably within many countries. However, we must acknowledge that there will always be some acceptable variations in the supply of health care because health care-especially specialist health carecannot be allocated entirely equally across all areas. None the less, efforts ought to be made to ensure that all areas/ regions are acceptably serviced by the range and quality of health care specified as necessary by the policy maker. Consequently, the following supply conditions must be met.

Firstly, healthcare resources must be distributed to regions according to population size, local input (for example, labour and capital) costs, healthcare needs, and (if groups defined by income are chosen as a relevant point of focus, and if it is found that income does indeed affect access) the income mix within each regional population, rather than any historical pattern of distribution towards relatively wealthy regions (subject to specific targeting of resources to supra-regional centres of excellence). As a corollary, local purchaser (that is, insurer) and provider use of healthcare resources must be monitored to ensure that the resources are used in a manner that is consistent with promoting equal access for equal need.

Secondly, efforts ought to be made to overcome any "inequitable" capacity constraints in "disadvantaged" areas, to ensure that there are incentives/directives for sufficient facilities and staff to locate and remain within these areas.

\section{The demand side}

Some commentators believe that the supply side is the only relevant consideration for securing equal access for equal need. ${ }^{8}$ However, we take the view that it is also important to consider the demand side, which primarily refers to the individual's ability to pay for health care. User charges are increasingly being used or mooted in many countries as a method by which to attempt to quell the demand for health care, but there is some evidence that charges have a higher impact on the demand for health care in lower income groups than in higher income groups. ${ }^{2}$ Assuming that the suppressed demand in the face of user charges is for needed health care (and that access to health care is not currently favourably biased towards the poor), the increase in or introduction of general patient user charges may well have a detrimental effect on the principle of equal access for equal need. In any circumstances where user charges are introduced, provision must be made for these to be means tested over the range of specified health services in a manner that is consistent with the accepted principle of equity. Similarly, waiting lists for the range of specified services should not significantly differ by income group (again, assuming that groups defined by income are a relevant point of focus).

Demand will also be influenced by factors such as knowledge, information, cultural beliefs, indirect financial costs (for example, travel costs), the opportunity cost of patients' time (for example, foregone wages), and their preferences. The healthcare policy maker ought to attempt to address some (but not all-genuine underlying preferences) of these factors by providing, for example, targeted healthcare information and health promotion messages (subject to their value for money). It may well be the case that in many countries, for at least some illness categories, the relatively poor are less adept than their wealthier counterparts at taking advantage of healthcare services. Admittedly, more research is needed on this issue, and attempts ought to be made to ascertain the relative extent to which any observed income related differentials in healthcare utilisation (and non-utilisation) are the consequence of differential opportunities, or differential preferences. 
Moreover, the policy maker ought to be sensitive to culturally significant factors that may influence an individual's willingness to access health care. This is a particularly pertinent issue when considering differential access across groups defined by ethnicity (for example, Asian women may feel uncomfortable with the idea of visiting a male general practitioner), but the general issue may also be relevant when considering groups defined by income, social class, etc.

As a final issue relating to the demand side, the policy maker should also be aware of, and possibly compensate or legislate for, relatively poor patients who face large indirect financial and/or opportunity costs in seeking and receiving treatment.

\section{METHODOLOGICAL PROBLEMS THAT MUST BE RESOLVED}

For the future development of policy, the main methodological problems cited in the academic literature regarding equal access for equal need are twofold..$^{8}$

Firstly, the further development of, and consensus on, the definition of healthcare need is required, as is its consequent measurement. If consensus can be reached on a definition of healthcare need, healthcare policy makers will be in a better position to formulate policy that is not only more consistent with providing equal access for equal need (that is, horizontal equity), but that is also more consistent with providing appropriately disproportionate access across those with different levels of need (that is, appropriate unequal access for unequal need; in other words, vertical equity).

Secondly, the further development of good measurements of access are needed, which will require healthcare policy makers to specify explicitly the minimum relevant range and quality of health services that ought to be available to the population under their jurisdictions, the maximum levels of inconvenience and cost to be borne by patients in securing those services, and the minimum amounts of information that the population ought to hold to take advantage of those services. Research on equity of access has thus far used utilisation to approximate access because utilisation is easier to observe. However, as noted above, the principle of equal utilisation for equal need does not account for acceptable variations in the use of health care, and consensus is required in defining the reasons for these acceptable variations. Conversely, many unacceptable reasons for variations in the use of healthcare use will also have to be addressed at the level of both the supply side and the demand side (as outlined earlier).
In this article, we have focused mainly on groups defined by income, geographical residence, and (to a lesser extent) ethnicity, but in time, attempts ought to be made to widen the focus of these methodological challenges to consider other groups, including, where appropriate, those defined by (for example) education, gender, and lifestyle. Indeed, policy makers in some countries may decide that a focus upon one or more of these other groups ought to take precedence so as to accord with the dominant values of their country context(s). None the less, it is clear that, in all countries, there is much to do to appropriately define, improve, and secure, equity of access to healthcare services.

\section{ACKNOWLEDGEMENTS}

We are indebted to Julian Le Grand and Walter Holland for their comments on previous drafts of this article.

\section{Authors' affiliations}

A Oliver, E Mossialos, London School of Economics, London, UK

Funding: none.

Conflicts of interest: none declared.

\section{REFERENCES}

1 International Forum on Common Access to Health Care Services. Programme statement. Stockholm: IFCAHCS, 2003. http://www.social.regeringen.se/ inenglish/forum/indexhtm (accessed 23 Oct 2003).

2 Mossialos E, Thomson S. Access to health care in the European Union: the impact of user charges and voluntary health insurance. In: Gulliford M, Morgan M, eds. Access to healthcare. London: Routledge, 2003.

3 Mooney G. Equity in health care: confronting the confusion. Effective Health Care 1983;1:179-85.

4 Culyer AJ. Equity-some theory and its policy implications. J Med Ethics $2001 ; 27: 275-83$.

5 Department of Health. Inequalities in health: report of an independent inquiry chaired by Sir Donald Acheson. London: The Stationery Office, 1998.

6 Mooney G, Hall J, Donaldson C, et al. Utilisation as a measure of equity: weighing heat? J Health Econ 1991;10:475-80.

7 Whitehead M, Evandrou M, Haglund $B$, et al. As the health divide widens in Sweden and Britain, what's happening to access to care? BMJ 1997;315:1006-9.

8 Goddard M, Smith P. Equity of access to health care services: theory and evidence from the UK. Soc Sci Med 2001;53:1149-62.

9 Bradshaw J. A taxonomy of social need. In: McLachlan G, ed. Problems and progress in medical care. London: Oxford University Press, 1972.

10 Doyal L, Gough I. A theory of human need. London: MacMillan, 1991.

11 Carr-Hill R, Rice N, Smith P. Towards locally based resource allocation in the NHS. York: Centre for Health Economics, University of York, 1998.

12 Diderichsen F, Varde E, Whitehead M. Resource allocation to health authorities: the quest for an equitable formula in Britain and Sweden. BMJ 1997; 315:875-8.

13 Nord E. Cost-value analysis in health care: making sense out of QALYs. Cambridge: Cambridge University Press, 1999. 